\title{
LA RED DE SERVICIOS SECRETOS ESPAÑOLES DURANTE LA GUERRA DEL RIF (1921-1927): LOS SERVICIOS ESPECIALES RESERVADOS DIRIGIDOS POR RICARDO RUIZ ORSATTI
}

THE NETWORK OF SPANISH SECRET SERVICES DURING THE RIFF WAR (1921-1927): THE SERVICIOS ESPECIALES RESERVADOS MANAGED BY RICARDO RUIZ ORSATTI

\author{
Julián Paniagua López \\ UNED-Guadalajara, España \\ ORCID: https://orcid.org/0000-0003-4934-3023
}

Recibido el 26-3-2017 y aceptado el 1-8-2017

Resumen: Durante la Guerra del Rif el ejército español contó con varios servicios de información y espionaje, sin embargo hasta 1925 no hubo una doctrina o metodología que sirviera para sistematizar y organizar la información para que fuera realmente útil de cara a los objetivos militares y políticos. Las consecuencias fueron muy graves, tales como total ineficacia y gasto de dinero. Tras varios fracasos, el Directorio Militar organizó unos eficientes servicios secretos que fueron dirigidos por un civil, Ricardo Ruiz Orsatti. En este artículo se analizará la red de espías de este organismo usando la metodología del análisis de redes sociales.

Palabras clave: Marruecos, Guerra del Rif, espionaje, análisis de redes sociales.

\begin{abstract}
During the Riff War the Spanish Army had several information and espionage services, however until 1925 there was not a doctrine or methodology to systematize and organize the information really usefull to get the military and politicians targets. The consequences were very serious, such as total inefficiency and waste of money. After several failures, the Military Directory organized an efficient secret services that were led by a civilian, Ricardo Ruiz Orsatti. This article will explore the network of spies of this organism using the methodology of social networks analysis.
\end{abstract}

Keywords: Morocco, Riff War, espionage, social network analysis. 


\section{Introducción. Metodología y fuentes de información}

Cuando España y Francia firmaron el acuerdo de Fez en 1912 en virtud del cual se establecía, no el Protectorado (como se le suele denominar), sino la Zona de Influencia de España en Marruecos ${ }^{1}$, España se comprometió a crear y ejercer una Administración ${ }^{2}$. Es muy importante distinguir la colonización de un territorio de la figura jurídica establecida en el ámbito internacional de la época denominada Protectorado ${ }^{3}$. La colonia era una forma de gobierno directa por parte de la potencia ocupante y pertenecía a ese Estado; era una provincia. Mientras que en el Protectorado el gobierno de la potencia ocupante era indirecto y, en teoría, se respetaban las instituciones y las formas culturales de la población autóctona. En consecuencia, la misión y el compromiso adquirido por España no era la conquista, sino el desarrollo social y económico, a cambio de obtener algún tipo de beneficio político o económico.

Tras la firma del acuerdo mencionado los militares españoles comenzaron a ocupar el territorio, pero se encontraron con tres problemas iniciales. En primer lugar ya había un conflicto bélico iniciado unos años antes. La población autóctona estaba armada y era muy beligerante contra todo lo que no fuera de su propia kabila ${ }^{4}$. Esta guerra, que duró de forma intermitente hasta 1927, condicionó toda la obra de España en Marruecos. Da-

${ }^{1}$ Debido al objetivo central de este artículo, no puedo extenderme en las relaciones entre España y Francia de aquella época, pero necesariamente hay que dejar establecido que, propiamente dicho, desde el punto de vista jurídico derivado del Acta de Algeciras de 1906, el Protectorado no era español sino francés. Este hecho condicionó en muchas ocasiones la política española en su intervención en el norte de Marruecos, como por ejemplo la insistente reivindicación por parte de España de la ciudad de Tánger, o la modificación de la frontera de ambas zonas en julio de 1926 tras la captura de Abd-el-Krim. Para un análisis jurídico y político del Protectorado y las relaciones entre España y Francia véase Carrasco González, 2013, pp. 57-79; Girault, 1979; Morales Lezcano, 1976. Para un análisis del Protectorado Francés véase Rivet, 1988; Gershovich, 2000.

2 Martín Corrales y González Alcantud, 2007; Torremocha Silva, 2008.

3 Vilanova Valero, 2006, p. 17.

4 Woolman, 1968; Ayache, 1981; Pennel, 2001 (original de 1986); Hart y Raha Ahmed, 1999; Campos Martínez, 2000; Madariaga, 2005; Madariaga, 2008; Madariaga, 2009; Blond Álvarez, 2012; Fontella Ballesta, 2012; Atienza Peñarocha, 2012; Caballero Echevarría, 2013. En todos estos estudios el lector podrá encontrar amplia y rigurosa información sobre los orígenes de la guerra, los conflictos entre los Estados europeos, las empresas y los marroquíes por la gestión de las minas del Rif y las de la zona de Melilla (ese fue el origen de la guerra, en realidad), desarrollo de las campañas militares, así como aspectos económicos y culturales. 
das las circunstancias, España tuvo desde el principio una contradicción muy difícil de resolver: había que «pacificar» el territorio usando las armas pero sin considerar, al menos teórica y políticamente, como enemigos a los pobladores autóctonos ${ }^{5}$.

En segundo lugar, a pesar de que la presencia de España en Marruecos databa de siglos atrás pero con más presencia desde mediados del siglo XIX, a principios del siglo XX los militares desconocían gran parte de la población y del territorio. Ni siquiera disponían de mapas fiables y el conocimiento de la población se restringía a las zonas de Ceuta, Melilla, Tánger y algo de Larache ${ }^{6}$.

Y, en tercer lugar, en ese momento el ejército no disponía de una doctrina o metodología para organizar y sistematizar la información, ni hubo una institución que la enseñara, como por ejemplo la Escuela Colonial que poseían los franceses desde el siglo XIX para formar a sus administradores coloniales. La Escuela de Interventores se creó años después de la implantación del Protectorado y tardó algunos años en alcanzar un nivel aceptable de organización ${ }^{7}$.

Todo estaba por hacer, desde la organización institucional hasta el desarme de la población; desde la construcción de una acequia, un camino o un puente, hasta la creación de una escuela o un dispensario médico. Desde el principio las autoridades españolas fueron conscientes de la enorme dificultad que suponía la intervención en Marruecos y, lo peor, el gasto que habría que realizar y el escaso beneficio que se iba a obtener. Primo de Rivera, por ejemplo, ya dijo en 1913 que la decisión más acertada sería abandonar Marruecos ${ }^{8}$. Sin embargo ya era tarde para tomar una decisión así. A pesar de los perjuicios que ya se habían producido incluso antes del convenio con Francia, como fueron los sucesos del Barranco del Lobo en 1909 y consecuencia de la semana trágica de Bar-

5 Hernández Mir, 1926; Goded Llopis, 1932; Gómez-Jordana Souza, 1976.

${ }^{6}$ Castillo Jiménez, 2014, p. 22-24. Este investigador comienza su estudio con el análisis de la Comisión Geográfica del Estado Mayor en Marruecos, creada en 1880, y se refiere a la ausencia, tanto de mapas como de otro tipo de información sobre la sociedad marroquí. Durante los primeros años los mapas usados fueron franceses, pero no eran completamente precisos.

7 Vilanova Valero, 2006; Castillo Jiménez, 2014. Algunos documentos de archivo que se pueden consultar para el problema de la metodología de los datos sociológicos, antes de la sistematización que realizó la Escuela de Interventores durante los años 30 están en las cajas A.G.A. 81/636 y 81/680.

8 Bachoud, 1988, páginas 134-135. 
celona $^{9}$, había que cumplir con los acuerdos firmados, porque en caso contrario España saldría más perjudicada en su prestigio internacional. Para poder llevar a cabo la obra a la que España se había comprometido era necesario ganar la guerra, y para ello se requería tener algo muy valioso: información.

Una de las funciones más importantes de los servicios de información es saber distinguir cual es la verdadera y comprobable, de la falsa. Asimismo, hay que tener algún criterio o método para procesar los datos, desde las primeras informaciones, que pueden proceder de cualquier fuente, hasta la información clasificada. Y, por último, hay saber hacer buen uso del conocimiento procesado, analizado, verificado y comprobado para que sea realmente útil, haciendo las relaciones precisas entre unos datos con otros, transferir esa información solo a las personas correspondientes y a su debido tiempo, para poder tomar las decisiones más adecuadas según los intereses del momento, y que todo ello implique el menor riesgo posible. Este trabajo de recogida, clasificación, análisis, y transmisión de la información, solo se puede hacer dentro de un organismo especializado ${ }^{10}$.

En la bibliografía sobre el Protectorado español y la Guerra del Rif solo hay un estudio dedicado íntegramente a este asunto, el citado de Castillo Jiménez, que descubrió hasta seis organismos de espionaje existentes desde 1912 hasta 1927, los cuales no siempre fueron eficaces e incluso hubo serias deficiencias de organización y coordinación entre ellos. En la bibliografía sobre la Guerra del Rif que he usado y citado en la nota 4 apenas hay mención a los espías y servicios secretos de ambos ejércitos. La ausencia de estudios es muy llamativa, llegándose a dar el caso de tener buenos análisis de conflictos posteriores, como la Guerra Civil española, pero encontrar afirmaciones como esta: «Durante años, y especialmente tras la rebelión rifeña de 1921, el ejército de campaña señaló la importancia de controlar el tráfico de armas y dinero hacia los rifeños. Esta podía ser una tarea para el servicio de inteligencia, civil o militar, de haber dispuesto de alguno ${ }^{11}$. Resulta bastante ingenuo pen-

9 Madariaga, 2005.

10 Navarro Bonilla, 2002; Navarro Bonilla y Esteban Navarro, 2004; Rosales Pardo, 2005; Santé Abal, 2015.

${ }^{11}$ Heiberg y Ros Agudo, 2006, página 1. Juan Alcalde (Alcalde, 2008) también tiene un libro que analiza los servicios secretos en España, pero a pesar de su título, realmente se centra a partir de la Guerra Civil. 
sar que el ejército de un Estado carece de algún servicio de espionaje. El ejército español dispone de espías desde al menos el siglo XVI ${ }^{12}$, y hasta la llegada de la máquina Enigma tanto el ejército como el cuerpo diplomático usaban un sistema de encriptación de mensajes basados en una tarjeta con coordenadas, verticales y horizontales, y unas claves específicas para aplicarlas que sustituían las sílabas por números. Otra cosa distinta es, como he indicado, la eficacia o la formación de los agentes que, a la vista de los documentos consultados, durante los primeros años no estaban del todo formados para el contexto de Marruecos. Pero el ejército sí tenía espías.

En este artículo se analizará uno de los servicios de espionaje más importantes que tuvo el ejército español durante la Guerra del Rif, los Servicios Especiales Reservados, dirigidos por un civil, Ricardo Ruiz Orsatti. El servicio estuvo activo desde octubre de 1924 hasta febrero de 1926. La fuente documental utilizada son los propios documentos elaborados por el equipo directivo de este servicio, junto con otros de las autoridades de la época, conservados en el Archivo General de la Administración (A.G.A.). Para facilitar la comprensión de la red de espías que se extendió por todo el territorio del Protectorado, he empleado el método del análisis de redes sociales, basado en la teoría matemática de grafos, y he incluido el gráfico correspondiente volcando los datos reticulares en el programa informático ucinet. Debido a la naturaleza de este artículo, he omitido el análisis cuantitativo de los datos que proporciona el programa ${ }^{13}$.

12 Sola Castaño y Varriale, 2015.

13 Aunque el método denominado análisis de redes sociales está siendo cada vez más usado, sin embargo es poco conocido en España y no se ha aplicado mucho en estudios históricos. Incluyo aquí una brevísima introducción para los lectores que desconozcan esta técnica. El método sociológico convencional se basa en el estudio de los actores y sus atributos. Una estadística, por ejemplo, está basada en esas categorías. El análisis de redes sociales incluye a los actores, sus atributos y las relaciones que tengan entre sí los actores, denominados nodos. En consecuencia el analista de redes tiende a ver a los actores inmersos en un conjunto de vínculos compartidos, directos o indirectos, con otros actores. Hay que recoger los datos empíricos del tipo de relación de cada par de actores que formen la red, se apoya en el uso de la teoría matemática de grafos, se procesan los datos a través de los programas informáticos especializados y, por último, se representa la red con un gráfico. El programa proporciona los datos estadísticos para su posterior análisis. Para una introducción a este método véase Wasserman \& Faust, 1997; Borgatti, Everett \& Freeman, 2002; Molina, 2001 y la página web en español http://www.revista-redes.rediris.es/ webredes 


\section{La creación de los Servicios Especiales Reservados ${ }^{14}$}

Como he indicado, siguiendo la línea de investigación iniciada por Castillo Jiménez, desde el inicio del Protectorado hasta el final de la guerra del Rif hubo hasta seis organismos durante ese periodo. Quienes se dedicaron primero a estas tareas fueron los Tabor de policía, pero muy pronto las autoridades pensaron en un servicio especializado. Fue el caso de la Oficina de Información de Tánger ${ }^{15}$, pensada en 1916 por el Alto Comisario, Francisco Gómez Jordana y por el cónsul de España en Tánger, Francisco Serrat, para tratar de controlar el problema de esa ciudad. Fue creada en 1919 y perduró hasta 1923. Aunque se pusieron medios materiales y se llegó a invertir hasta $85.308,88$ pesetas durante esos cinco años, sin embargo esa primera etapa fue un absoluto fracaso. Aparte de los conflictos administrativos por no haber concretado exactamente de quién dependía, si de la Alta Comisaría o de la Legación Española en Tánger, estaba el hecho de la inexperiencia del personal, que fueron frecuentemente engañados por los marroquíes que colaboraron con los españoles. Independientemente de la derrota en Annual en julio de 1921, no parece que el ejército tuviera mucha información veraz de como estaban armadas las harkas rifeñas, y era a los servicios secretos a quien le correspondía proporcionar esa información. Dos años más tarde, en abril de 1925, se reabrió la Oficina para reforzar las actividades de información y espionaje que se estaban llevando a cabo. En esta ocasión fue dirigida por el capitán Joaquín Miguel y se mantuvo hasta $1927^{16}$. Tras el final de la

${ }^{14}$ La documentación principal sobre los Servicios Especiales Reservados se encuentra en las cajas A.G.A. 81/673, 81/674, 81/675 y 81/676. Hay otros documentos en otras cajas pero en estas están los informes diarios que elaboraron los agentes. A lo largo del artículo especificaré la caja y el expediente concreto de algunos documentos citados.

${ }^{15}$ La documentación de esta Oficina se encuentra en las cajas AGA 81/10494 y en la $81 / 10495$. En la primera están los documentos de su origen y constitución y la segunda contiene cinco sobres correspondientes a los años 1919, 1920, 1921, 1922 y 1923, donde se conservan todas las facturas del material utilizado y el registro de todos los gastos, desde los botes de tinta hasta el salario de los espías. Se incluyen los pequeños cuadernos donde los agentes apuntaban el día, el informante y la propina que se le daba.

${ }^{16}$ Los documentos de la segunda etapa de la Oficina de Información de Tánger están muy desperdigados en el archivo. Algunos de ellos se encuentran en las cajas citadas en la nota 14, junto con los expedientes de los Servicios Especiales Reservados, pero la mayoría de ellos están en otras cajas y, lo peor para el investigador, no reunidos, sino mezclados con otros documentos no relacionados o parcialmente relacionados con el trabajo de la Oficina. 
guerra, oficialmente en julio de ese año, fueron cancelados todos los organismos de inteligencia e información y se unificaron en un solo, la Oficina Mixta Hispano Francesa, que fue creada en noviembre de 1925 a partir de los acuerdos con Francia de junio y julio de ese año. Fue ubicada primero en Málaga hasta 1929, y después se trasladó a Tánger. Perduró hasta el final del Protectorado en 1956 y funcionó como si fuera el ministerio del interior del Protectorado ${ }^{17}$.

En la página web del proyecto La historia trascendida, en su apartado de personajes históricos, se incluye a Ricardo Ruiz Orsatti. Ahí se nos dice que que nació en 1871 y murió en 1946, que fue maestro, inspector de enseñanza y periodista ${ }^{18}$. También aporta información sobre su hermano, Reginaldo, que fue traductor oficial de árabe. Otras de las ocupaciones que tuvo Ricardo Ruiz Orsatti fue la de jefe del Servicio de Higiene del ayuntamiento de Tánger. Escribió nueve libros, así como varios artículos periodísticos. Aparentemente fue un funcionario con un cargo importante en Tánger que cumplió con eficiencia su deber. Sin embargo, nada se dice de su trabajo para el Directorio Militar y la Alta Comisaría entre los años 1923 y 1926. A la vista de los documentos conservados y consultados, se puede sostener que Orsatti fue uno de los personajes clave de la Guerra del Rif, pero totalmente oculto. Como espía cumplió con el rigor de su oficio: formó a un equipo conocedor del terreno y de la sociedad, fiable, discreto y riguroso con las informaciones que recababa, sin transmitir ninguna que no hubiese sido verificada, o avisando de su relativa fiabilidad. Sus informes eran claros y precisos. También fue muy exigente con su equipo, llegando a despedir a algunos de ellos por hacer mal su trabajo. El objetivo final de un espía es el de aportar una información que detecte con precisión las acciones que vaya a hacer el enemigo; es decir, predecir comportamientos y, obviamente, sin que el enemigo lo sepa. Pero para llegar a transmitir esa información y poder analizar y relacionar los datos, se requieren muchos conocimientos, tanto de las personas involucradas como del entorno, y discreción, por supuesto. Orsatti cumplió con todos esos objetivos. Lo cual no

17 El expediente que contiene los documentos de creación, el reglamento y cartas de las autoridades se encuentra en la caja A.G.A. 81/689. Se incluye en este expediente también el traslado en 1929 a Tánger.

$18 \mathrm{http} / / / \mathrm{www}$.lahistoriatrascendida.es/personajes-historicos/ El documento de su nombramiento, el 19 de junio de 1917, como inspector de las escuelas árabes se encuentra en A.G.A. $68 / 324$. 
quiere decir que no fuera engañado en alguna ocasión, que lo fue. Pero su trabajo no resultó ser un desastre como la Oficina de Información de Tánger durante su primera etapa, sino todo lo contrario. Debido a las informaciones recogidas por el equipo que Orsatti dirigió, las acciones bélicas pudieron ser orientadas a objetivos militares concretos y a frustrar el contrabando, evitando con ello ataques indiscriminados. Llevó a cabo dos servicios. El primero fue un intento de establecer la paz con los rifeños en octubre de 1923, al que me referiré muy brevemente. El segundo fue la dirección de los Servicios Especiales Reservados, nombre del organismo de información y espionaje que le encargó formar y dirigir Primo de Rivera.

En marzo de 1923 una delegación de rifeños encabezada por el hermano menor de Abd-el-Krim, M'Ahammad, viajaron a París para comprar armas y establecer contactos con empresarios mineros. Fue acompañado por Bel Hadj-el-Hitmi, ministro de Asuntos Exteriores de la República del Rif, Mohammed Boudjibar, ministro de Finanzas y Economía y el Xerif Tidyani ${ }^{19}$, un tunecino rico que había estudiado en París y, al parecer, tenía contactos con empresarios y hombres de negocios. El año anterior Abd-el-Krim lo había nombrado representante de la República del Rif para las negociaciones con Francia y la Sociedad de Naciones. El viaje no lo hicieron los cuatro juntos, sino por pares, M'Ahammad Abd-el-Krim y el Hitmi llegaron antes a París, lo más probable por la ruta Orán y Marsella; mientras que Boudjibar y Tidyani lo

${ }^{19}$ En la bibliografía sobre la Guerra del Rif hay información sobre este asunto, pero oscila desde la simple mención, caso de los generales Goded (Goded, 1932, p. 79) y Jordana (Jordana, 1976, p .72), hasta la insuficiente o incompleta. Sueiro Seoane menciona el intento de acuerdo de paz y se ajusta a lo que dicen los documentos, pero su descripción es muy breve (Sueiro Seoane, 1993, pp. 142-144). Rosa Madariaga también abordó este episodio (Madariaga, 2009, pp. 326-337), pero se centró únicamente en la parte folclórica de la esposa de Tidyani, a quien tildó de estafador porque desapareció y «nunca más se supo de él», y a Orsatti de fracasado. Dejó sin analizar lo más importante, el intento de paz. La información sobre este asunto se encuentra en las cajas A.G.A. 81/9979, 81/9981 (en esta caja es donde se incluye el expediente del viaje desde París a Madrid, la preparación del viaje de Tidyani al Rif, la propuesta de paz española y la respuesta de Abd-el-Krim, fechada el 24 de abril de 1924), 81/9984, 81/10431, 81/10598 y la 81/12710. En esta última se encuentra el expediente titulado «Notas referentes a Mulay Mohammed Ben Mulay Mohammed Chej Salah Tiyani. Cherif Tiyani», que es un largo informe de 70 páginas en el cual se resume todo el asunto. Se incluye la traducción del interrogatorio que le hizo el coronel Sebastián Prats, Jefe de la Oficina Central de Intervención y Fuerzas Jalifianas, Sección Primera de Melilla en julio de 1926. 
hicieron por Casablanca, hasta Gibraltar y del peñón a Marsella (de la vigilancia a estos dos últimos hay constancia documental, por eso he escrito en la frase anterior «lo mas probable»). La delegación rifeña estuvo vigilada por los espías contratados por la embajada de España en Francia, dirigidos por el embajador José María Quiñones de León. Orsatti viajó a París de incógnito, el único que conocía su presencia fue Tidyani. El embajador solo supo que ambos estuvieron en contacto cuando regresaron a Madrid, en octubre de ese año. Fue Jordana quien informó a Quiñones de su presencia y de los plantes que tenían. A su regreso de París, Orsatti, Tidyani y la esposa de éste se entrevistaron en Madrid con Jordana y con Primo de Rivera, y éstos entregaron al tunecino un documento con diez puntos en los que se proponía la paz y el establecimiento de un gobierno autónomo en el Rif, pero respetando los acuerdos internacionales vigentes. Viajaron después a Melilla y organizaron la expedición. Se fletó un barco con dos tripulantes que transportaron al Xerif, a su ayudante y unos paquetes con regalos para las mujeres de Abd-el-Krim. Cuando los desembarcaron en una playa el barco regresó a Melilla y ellos se adentraron en el Rif y, aparentemente, desaparecieron. Mientras Tidyani estuvo en el Rif, su esposa vivió en el lujoso hotel Regina de Málaga, con una asistenta para su hija, todos los gastos pagados por el ejército y con la suficiente libertad de movimientos como para verse con cierta frecuencia dos amantes. Unos meses después, debido a la ausencia de noticias de su marido, fue deportada a Túnez.

Sin embargo Tidyani no desapareció, sino que cumplió con el objetivo encomendado: conseguir que la propuesta de paz llegara a las manos de Abd-el-Krim. Según el relato del propio Tidyani, cuando se encontró con el líder rifeño, este lo trató muy amablemente, hasta que le entregó la propuesta de paz. Como no podía ser de otra manera, fue en ese momento cuando descubrió que había sido traicionado. Fue torturado y encarcelado y su asistente murió apaleado. Diez meses después del desembarco de Alhucemas fue liberado por el ejército, cuando ocuparon la kabila de Beni Urriaguel. Tidyani no fue un estafador, sino un doble agente que fue utilizado por el ejército a través de la intervención de Orsatti, la cual fue determinante para que el tunecino traicionara a los rifeños y fuera él y no otra persona quien arriesgara su vida al adentrarse en el Rif. Por último, y tal vez más importante, fue el mensaje que se enviaba desde el gobierno español a Abd-el-Krim: un supuesto aliado de los rifeños desde hacía muchos meses, con aparentes contactos con las autoridades francesas y con hombres de negocios del sector minero, trabajaba en realidad a favor de 
España y estaba controlado por los militares españoles. Con este hecho - la traición de un aliado - España estaba demostrando que la guerra no solo se estaba llevando a cabo en los campos de batalla, sino también en los despachos, y ahí los rifeños tenían todas las de perder.

La idea original de los Servicios Especiales Reservados data de septiembre de 1924, y por los documentos conservados, todo apunta a que fue el mismo Primo de Rivera quien dio la orden para organizarlos. En esa fecha, Abd-el-Krim estaba en el momento más álgido de su poder. El ejército español permanecía estancado, sobre todo en la zona de Xauen, sin ser derrotado, pero sin poder avanzar, o con graves riesgos cuando lo hacía. El sistema de ocupación del territorio a través de los blocaos no estaba siendo eficiente, porque quedaban aislados y era muy difícil su abastecimiento. Además de eso, durante los meses anteriores, el inglés Charles Gardiner, a pesar de la vigilancia, ya había alcanzado por dos veces las costas de Alhucemas dejando un importante cargamento de material de guerra, sobre todo cable telegráfico y equipos de radiotelegrafía sin hilos, con lo cual las harkas rebeldes estaban comunicadas y coordinadas desde el campo con el cuartel general de los rifeños en Axdir $^{20}$. Tánger estaba totalmente descontrolado y desde sus dos zocos se organizaban acémilas que enviaban todo tipo de mercancías a las kabilas rebeldes. Apenas un mes después, en noviembre, el ejército se retiró de Xauen, maniobra que ha sido interpretada como una derrota, un movimiento defensivo para evitar un nuevo desastre como el de Annual $^{21}$. Aunque fue criticada por una parte del ejército, en realidad fue la decisión estratégica correcta y el inicio de la victoria sobre la rebelión de Abd-el-Krim. La situación no podía continuar así ya que había demasiado dinero gastado, demasiadas vidas perdidas y demasiado prestigio cuestionado.

La creación de los Servicios Especiales Reservados puede llevar a confusión con otro organismo formado paralelamente por aquellas mismas fechas, como fue la Comisaría General de Vigilancia del Litoral de Andalucía y de Marruecos. En el expediente que contiene los documentos en los que se dio la orden para la creación de la Comisaría, también se in-

20 La información sobre el contrabandista Charles Gardiner se encuentra en las cajas 81/9979 y 81/9980. No se pueden citar los expedientes de estas cajas porque, literalmente, no hay expedientes, sino un cúmulo de documentos.

21 Fernández Riera, 2013. 
cluyen los documentos de creación de los Servicios Especiales Reservados. El telegrama en el cual se envió la orden es este ${ }^{22}$ :

«Madrid de residencia Tetuan $28 / 9 / 924=$ Presidente Directorio a Presidente Interino $=$ Es importantísimo pues en los puertos de nuestra costa (Cádiz, Algeciras, Almería, Málaga) y en Céuta y Melilla y aquí se establezca una estrecha y especial vigilancia que nos tenga al tanto del servicio intensísimo de espionaje y de las mil tramas formadas para alentar y socorrer al enemigo = para ello sería convenientísimo que a las órdenes de un hombre experto de lo mejor con que cuente el jefe de seguridad, se organice una brigada especial durante tiempo que duren estas circunstancias en relación directa con el Alto Comisario ruegole que con todo interés y de acuerdo con el General Martínez Anido se organice urgentemente este servicio sin escatimar gastos pues asunto muy descuidado al que concedo gran interés $=$ Complemento de este servicio es una policía de Tánger la que podría formar parte de esta misma brigada y aparecer afecta al Consulado General.»

Se conserva otro telegrama con una redacción muy similar, fechado al día siguiente y enviado por el General Muslera. Hubo además una filtración a la prensa informando sobre la creación de la mencionada Comisaría con sede en Sevilla y dirigida por Adolfo de Miguel que se ocuparía de la vigilancia en las costas andaluzas y marroquíes. No gustó nada esa filtración, y días después, el 17 de octubre de 1924, Primo de Rivera envió una carta al general Martinez Anido, que está incluida en el mismo expediente citado, en la cual le hablaba de la creación de ese servicio especializado. Dice así:

\section{«RESERVADO}

Tetuán 17 de octubre de 1924

Excmo. Señor Don Severiano Martínez Anido.

Querido Severiano:

Hoy se me ha presentado el Sr. De Miguel, nombrado para la Sección de Policía especial del Sur de España y plazas de nuestro litoral africano.

22 Caja A.G.A. 81/674, expediente titulado en la carpetilla original «Organización de un servicio de Policía contra espionaje en los puertos de Almería, Málaga, Algeciras, Cádiz, Ceuta y Melilla». 
Indudablemente hemos enfocado mal este asunto de tanto interés para nuestra acción en Marruecos, pues tal como se ha organizado creo ha de resultar completamente inútil. Esa Policía debe en realidad organizarse, y así pienso yo hacerlo desde luego, dependiendo del Alto Comisario y siendo cargo su sostenimiento al Presupuesto de la Zona de Protectorado, cuando haya crédito para ello, y por lo pronto a los fondos políticos de carácter reservado.

Su Jefe debe ser hombre conocedor del País y del idioma, y ya tengo yo en estudio el candidato, y tener agentes moros, hebreos o europeos de distintas nacionalidades en Tánger, Tetuán, Melilla, Céuta, Gibraltar, Arcila, Larache, Alcazar y aún en el extranjero y en las plazas nuestras del litoral (Algeciras y Málaga).

Estos agentes deben ser lo menos conocidos posible, dándose a conocer a la Policía y Autoridades de la Península o de soberanía o a nuestros Cónsules o representantes diplomáticos, cuando necesiten algún auxilio, por medio de carnet firmados por mí como Alto Comisario.

De ese modo todas las informaciones, debidamente coordinadas por la Jefatura y controladas por el Alto Comisario con las que reciba de los Cónsules y Oficina de Marruecos, conducirán al conocimiento de pistas y adopción de medidas, que solo a base de un perfecto conocimiento del País y de su política pueden adoptarse.

Estimo pues, que esa nueva sección de Policía debe desde luego disolverse empleándose en otros menesteres las utilidades de su personal, que indudablemente será competentísimo para los usos corrientes.

Creo estarás de completo acuerdo conmigo, lamentando la perturbación que puede suponer esta rectificación de normas aconsejada por la experiencia que voy adquiriendo en la intensísima labor que aquí realizo.

De esta carta mando copia al Marqués de Magaz para su conocimiento y el de la Oficina de Marruecos, que es a quien ha de interesar principalmente la nueva organización.

Te abraza cariñosamente tu amigo y compañero.»

Castillo Jiménez cita esta carta parcialmente ${ }^{23}$, pero la vincula a la creación de la Comisaría de Vigilancia del Litoral. En realidad Primo de Rivera está rectificando, como él mismo dice al principio de la carta, cuando cita la conversación que mantuvo con Adolfo de Miguel, así como en el penúltimo párrafo. En quien está pensando es en Orsatti ( «ya tengo yo en estudio el candidato»), porque indica lugares donde después éste distribuyó a sus agentes, de diversas nacionalidades, religiones y conoce-

23 Castillo Jiménez, 2014, p. 156. 
dores de idiomas. Ese mismo día el general Jordana envió un telegrama a Orsatti diciendo «Presidente desea venga Vd. para conferenciar con él. Tramitase de O. de S.E. El Comandante E.M.». En cualquier caso, ambos organismos fueron creados en octubre de 1924 con la intención de poner todos los medios para que el servicio de espionaje en la Zona funcionara con eficacia.

¿Quién recomendó a Primo de Rivera que el mejor candidato para ese servicio especializado sería Orsatti? En primer lugar fue el coronel Ovilo, que estaba destinado en la comandancia de Málaga, sede del centro de información secreta del ejército (por este motivo, un año más tarde, cuando se creó la Oficina Mixta Hispano-Francesa, se ubicó en Málaga). Ovilo y Orsatti eran tangerinos de nacimiento y se conocían desde la infancia. La segunda persona que recomendó a Orsatti fue un pariente suyo, el coronel retirado José Álvarez Cabrera; conocía su formación y su personalidad. Asimismo, su experiencia anterior en su misión en París y Melilla con Tidyani coadyuvó a su elección. El nombramiento oficial de Orsatti fue el 21 de octubre de 1924.

El siguiente paso fue formar el equipo. Se contactó primero con Angelo Ghirelli, un arabista italiano que ya había trabajado para los militares españoles entregándoles informes antes de las campañas de 1921, y que en aquel momento trabajaba como informador para la Comandancia de Melilla dirigida por el general Sanjurjo. Para evitar toda sospecha, Orsatti y Ghirelli tuvieron su primera reunión en Algeciras, y allí acordaron la organización de la zona oriental, de la cual el italiano sería el jefe. Ya tenía varios agentes desplegados en la zona, por lo que a partir de ese momento el nuevo servicio quedaría reforzado con cinco agentes más bajo su dirección que se desplegarían desde Melilla hacia el sur hasta Taurirt, más el área de Uxda, Orán y Tlemecén. Estas tres ciudades quedaron a cargo del cónsul de Orán que colaboraría con Ghirelli. Se acordó que cada uno de los agentes cobraría 150 pesetas mensuales, más una gratificación de 50 pesetas para el agente de Melilla, 200 pesetas mensuales para gastos de viaje y el salario del italiano que pidió 1.000 pesetas al mes, pero en los documentos de la contabilidad del servicio aparecen solo 750 .

Una vez formado el equipo de la zona oriental, había que formar el de la zona occidental. Había varias áreas: Tánger, kabilas cercanas, Casablanca y el sur de la península. Orsatti envió un informe ${ }^{24}$ a Primo de

${ }^{24}$ Este informe se encuentra en la misma caja y expediente citado en la nota 22. 
Rivera en el cual proporcionaba detalles de cada uno de los agentes. En Algeciras el agente sería el alcalde, Emilio Morilla, «de probado patriotismo y ferviente monarquismo». En Gibraltar, Alfredo Abecasis. Los Abecasis eran una familia de orígenes hebreos, residentes a la vez entre la Línea de la Concepción y Gibraltar dedicados al tráfico marítimo en el Estrecho. En el pasado, el abuelo, apodado «El Morito», fue un conocido contrabandista. Orsatti se refería a ellos como «no son cuáqueros precisamente» y reconocía que por los antecedentes familiares no sería muy recomendable este agente, pero consideraba que podría servir para ciertas informaciones del tráfico marítimo. En Tarifa Orsatti contactó con Marcial Martí, que era amigo personal suyo y era el administrador de correos. Y en Cádiz contactó con Manuel Lancho, sin aportar referencias sobre él. También se refirió a Ghirelli, de quien no se fiaba, y le insistió que su labor consistía en recabar datos sobre las actividades anti españolas realizadas por marroquíes o europeos, tarea únicamente informativa, jamás ejecutiva. A pesar de la gran desconfianza que se tenía en Angelo Ghirelli, no obstante era el mejor agente que los militares españoles tenían en aquel momento en la zona oriental. Ghirelli estaba obligado a entregar los informes a Orsatti y, además, el italiano tenía dos interlocutores más, únicamente para casos de urgencia: el comandante general de Melilla, general Sanjurjo, y el coronel Ovilo, de la comandancia de Málaga. También contactó con el coronel Orgaz en Tetuán, pero solo para asuntos pecuniarios.

No fue complicado reclutar agentes para la zona de Tánger, porque tanto Orsatti, como su pariente, el coronel jubilado José Álvarez, tenían los contactos suficientes en la ciudad. Destacaba entre todos ellos Renaud Von Motz, que era cuñado de Orsatti, de nacionalidad holandesa y hablaba correctamente holandés, alemán, inglés, francés, español y árabe. Estuvo a cargo de Tánger y Tetuan y en primer lugar contactó con un dentista americano amigo suyo establecido en Tetuan, pero del que se tenía la sospecha de estar relacionado con algunos alemanes que podrían estar conspirando contra España. A pesar de su apellido de origen germánico, podría aparentar desconocer el idioma y recoger conversaciones reveladoras. Favorecía su situación el hecho de haber tenido en el pasado un percance con las autoridades españolas en Larache, por cuyo error tuvo que ser indemnizado, lo cual le permitía pasar a la vista de la gente como desafecto a los españoles. En otros informes posteriores, Orsatti dijo que Von Motz era el mejor de sus agentes. La organización completa y definitiva quedó finalizada en diciembre, tras una reunión que ce- 
lebró Orsatti en Madrid con el General Jordana, con el director de la Oficina de Marruecos, Aguirre de Cárcer, y con el jefe de Seguridad, José González Hernández. También se entrevistó al regreso en Córdoba con Adolfo de Miguel, el jefe de la Comisaría de Vigilancia del Litoral. Tras esas reuniones, Orsatti informó en una carta a Primo de Rivera en la cual quedó fijado el nombre del organismo, la necesidad de que él quedara totalmente oculto, que los agentes debían comunicarse con el ex coronel José Álvarez, que sería el interlocutor de todos ellos, y que fueran muy pocos los agentes que supieran que él era el destinatario final de toda la información. También pidió la elaboración de un carnet para sus agentes y que pudieran viajar gratis sin ser registrados en los puestos de aduana y en los barcos usando el carnet de agente de los Servicios Especiales Reservados.

\section{La red de espías en el territorio}

En la siguiente tabla presento la lista completa de todos los integrantes del organismo, tanto los que pertenecían formalmente a él, nombrados o elegidos, como los que participaron o colaboraron. Están clasificados por la función que desempeñaron dentro del organismo y la ubicación desde la que trabajaban, esos son sus atributos. En términos de análisis de redes sociales, es una red con enfoque realista (en oposición al nominalista), porque, salvo que en el futuro se descubran nuevos documentos y, por consiguiente, en ellos aparezcan nuevos actores, los que se citan en la tabla de la página siguiente son los que intervinieron en el servicio.

El trabajo estaba dividido en siete funciones, de tal manera que un actor podía tener varias a la vez. Eran, como indica la segunda columna, director, jefe de zona oriental, secretario, espía, receptor de la información, analista y enlace. Las funciones de director, jefe de zona oriental y secretario solo las poseían Orsatti, Ghirelli y José Álvarez respectivamente y eran los cargos formales que tenían en el organismo. Espía es el que recaba la información y la emite a la persona correspondiente. Receptor de la información es el que la recibe, pero ni la envía a otro actor (solo tienen esta función el general Jordana y Primo de Rivera), ni la procesa. El enlace es quien recibe una información y la pasa a otro actor tal y como la recibe, sin modificarla. Analista es el que la analiza, procesa y clasifica para enviar solo la relevante e importante. 
Tabla 1

Actores de la red

\begin{tabular}{|c|c|c|}
\hline Agente & Función y atributos & Ubicación \\
\hline Ricardo Ruiz Orsatti & Director, analista, enlace & Tánger. \\
\hline Angelo Ghirelli & $\begin{array}{l}\text { Jefe de la zona oriental, espía, } \\
\text { enlace }\end{array}$ & Melilla. \\
\hline $\begin{array}{l}\text { Agente marroquí, nombre } \\
\text { desconocido }\end{array}$ & Espía & $\begin{array}{l}\text { Taourirt-Guerif (zona } \\
\text { oriental). }\end{array}$ \\
\hline $\begin{array}{l}\text { Agente marroquí, nombre } \\
\text { desconocido }\end{array}$ & Espía & $\begin{array}{l}\text { Saïdira y Port-Say (zona } \\
\text { oriental). }\end{array}$ \\
\hline $\begin{array}{l}\text { Agente marroquí, nombre } \\
\text { desconocido }\end{array}$ & Espía & $\begin{array}{l}\text { Cabo de Agua (zona } \\
\text { oriental). }\end{array}$ \\
\hline $\begin{array}{l}\text { Agente marroquí, nombre } \\
\text { desconocido }\end{array}$ & Espía & $\begin{array}{l}\text { Zaio y Ulad Zattut (zona } \\
\text { oriental). }\end{array}$ \\
\hline $\begin{array}{l}\text { Agente marroquí, nombre } \\
\text { desconocido }\end{array}$ & Espía & $\begin{array}{l}\text { Ain Zorah y Ul'sun (zona } \\
\text { oriental). }\end{array}$ \\
\hline $\begin{array}{l}\text { Agente marroquí, nombre } \\
\text { desconocido }\end{array}$ & Espía & Melilla 1 (zona oriental). \\
\hline $\begin{array}{l}\text { Agente marroquí, nombre } \\
\text { desconocido }\end{array}$ & Espía & Melilla 2 (zona oriental). \\
\hline $\begin{array}{l}\text { Agente marroquí, nombre } \\
\text { desconocido }\end{array}$ & Espía & Melilla 3 (zona oriental). \\
\hline General Sanjurjo & Enlace & Comandancia de Melilla. \\
\hline Vicecónsul Oujda & Enlace & Oujda. \\
\hline $\begin{array}{l}\text { Agente, nombre descono- } \\
\text { cido }\end{array}$ & Espía & Tremecén. \\
\hline $\begin{array}{l}\text { Agente, nombre descono- } \\
\text { cido }\end{array}$ & Espía & Orán. \\
\hline José Álvarez & Secretario, espía, enlace & Tánger. \\
\hline Von Motz & Espía & Tánger. \\
\hline Thomas Lionne Reade & Espía & Tánger. \\
\hline Carlos Arenas & Espía & Tánger. \\
\hline
\end{tabular}




\begin{tabular}{l|l|l}
\hline \multicolumn{1}{c|}{ Agente } & \multicolumn{1}{|c}{ Función y atributos } & \multicolumn{1}{c}{ Ubicación } \\
\hline El Arua & Espía & Beni M'sauar y Uadras. \\
\hline Ahmed Xaabá & Espía & Anyera y Hauz. \\
\hline El Filali & Espía & Tánger. \\
\hline El Arbi & Espía & Tánger. \\
\hline El Aiaxi & Espía & Anyera y Uadras. \\
\hline Mohammed Darkaui & Espía & Diversas kabilas. \\
\hline Luis Ruiz & Espía & Casablanca. \\
\hline Emilio Morilla (sustituido & Espía & Algeciras. \\
\hline Alfredo Abecasis & Espía & Gibraltar. \\
\hline Marcial Marti & Espía & Tarifa, correos. \\
\hline Manuel Lancho & Espía & Cádiz. \\
\hline Adolfo de Miguel & Enlace & Sevilla. Comisaría de Vi- \\
gilancia del Litoral.
\end{tabular}

La información que circulaba en esta red era de tres tipos. El primero eran las órdenes que daban los jefes a los subordinados, que se puede sintetizar como «tienes que investigar tal asunto». No obstante este tipo de órdenes se dio muy pocas veces porque desde el principio se acumuló el trabajo y los espías supieron muy bien cual era su cometido y qué información recabar. El segundo era el informe que entregaban los subordi- 
nados a los jefes, en dos aspectos: el primero era el informe de espionaje propiamente dicho, los datos brutos recogidos por los espías; el segundo era el informe con una primera clasificación que enviaban los jefes de los espías (Orsatti y Ghirelli, pero más el primero) a los analistas de la Intervención General y Fuerzas Jalifianas dirigidas por el coronel Orgaz. El tercero era, el informe final, ya analizado y procesado, que se entregaba al Directorio Militar (Primo de Rivera y el General Jordana) y al general jefe de operaciones del Ejército de África. Por último, el general jefe de operaciones enviaba la información o bien al ejército de tierra o bien a la aviación para realizar las operaciones concretas, que podía ser una razzia, una emboscada, un bombardeo o vigilar un lugar determinado.

La ruta de la información fue la siguiente: Orsatti daba instrucciones a sus subordinados inmediatos, Ghirelli, José Álvarez y Von Motz; después Ghirelli se las comunicaba a sus agentes en la zona oriental y José Álvarez a los agentes en la zona occidental y a los de la península. Los espías recogían la información en la zona que tuvieran asignada y se la entregaban a sus jefes inmediatos. En el siguiente paso, Ghirelli redactaba el informe y se lo enviaba a Orsatti; en la zona occidental quien recibía los informes era José Álvarez, que después se los entregaba a Orsatti y éste redactaba el informe. El agente Von Motz hablaba con ambos indistintamente. Orsatti también podía recibir instrucciones de la Alta Comisaría para que ordenara a su vez a sus agentes investigar algo, pero tenía total autonomía, porque, como he indicado, desde el primer momento comenzaron a llegar una gran cantidad de datos que había que procesar y analizar; el trabajo se acumuló muy pronto. Una vez que Orsatti había redactado sus informes, con un primer filtro y clasificación, los entregaba al coronel Orgaz y era analizada por el comandante Rivera. En resumen la información transcurría a través de seis pasos: agente espía; ex coronel Álvarez y Ghirelli; Orsatti; Servicio de Intervención y Tropas Jalifianas (comandante Rivera y coronel Orgaz); Directorio Militar y general jefe de operaciones; y, por último, ejército de tierra o aviación que ejecutaba las órdenes del general jefe de operaciones.

También había una jerarquía en la información. ¿Cuál era la información prioritaria? En primer lugar, toda aquella que implicara conocer los planes del enemigo. En segundo lugar, toda aquella que implicara desarmar al enemigo. No obstante, los espías recogían información de todo tipo, como por ejemplo planes de ataque de alguna harka, movimiento de tropas, acémilas y traslado de mercancías, contrabando, precios de las mercancías en los zocos, abastecimiento de alimentos y productos de pri- 
mera necesidad, depósitos de armas, reuniones de extranjeros con rifeños, consecuencias y efectos tras los bombardeos y estados de ánimo en la población respecto a si apoyaban o no la rebelión de los rifeños. El trabajo principal de Orsatti y Ghirelli, aunque lo hizo más el primero, fue realizar correctamente esa primera clasificación, saber qué era lo urgente, qué era lo importante, qué era lo complementario.

Para elaborar la matriz de la red solo he utilizado los valores 1 y $0 . \mathrm{Se}$ podrían usar más valores para diferenciar el tipo de información que circulaba, sin embargo eso no afecta a la estructura relacional propiamente dicha. El 1 representa el envío de información, tanto de los primero datos brutos de los espías, los primeros informes de Orsatti y Ghirelli y la información ya procesada y analizada. He soslayado, por redundante, la orden primera a la que me he referido del jefe al subordinado. Al eliminar esa primera orden, la red es necesariamente asimétrica, porque los espías envían información, pero no la reciben. Los nodos están divididos en siete grupos, organizados según el lugar donde trabajaban: en rojo el grupo directivo (Orsatti, Ghirelli, Álvarez); en azul los espías de la península; en rosa la zona de Tánger; en verde los espías distribuidos en las kabilas de Yebala; en azul los espías de la zona oriental y Melilla; en amarillo la zona de Orán; y en marrón los militares. La dirección de la flecha, obviamente, indica la dirección de la información, nodo emisor y nodo receptor. La red esta representada en la figura de la página siguiente.

Como podemos observar, no fue una red excesivamente compleja, sobre todo porque necesariamente no todos los actores podían ni debían estar comunicados entre sí, aunque operaran en la misma zona. Lógicamente, el grupo que más comunicación tenía entre sí eran los militares, representados en la parte superior central del gráfico.

Durante el primer mes de funcionamiento, Orsatti se comunicaba directamente con Primo de Rivera, pero luego éste derivó la recogida de los informes en el comandante Rivera, que fue en realidad el verdadero analista del organismo, y al coronel Orgaz. En la redacción de las cartas entre Orsatti y Orgaz se percibe mayor frialdad. Nunca hubo conflictos entre ellos, la relación siempre fue cordial, pero fue mucho más profesional y formal. En cambio, en la correspondencia entre Orsatti y Primo de Rivera se percibe más calor amistoso y muchos menos formalismos. Finalmente la información, ya filtrada y contrastada, la recibían en primer lugar y con urgencia, el general jefe de operaciones del ejército de África en Tetuán y, posteriormente la recibían Primo de Rivera (excepto ese primer mes) y el general Jordana en Madrid. 


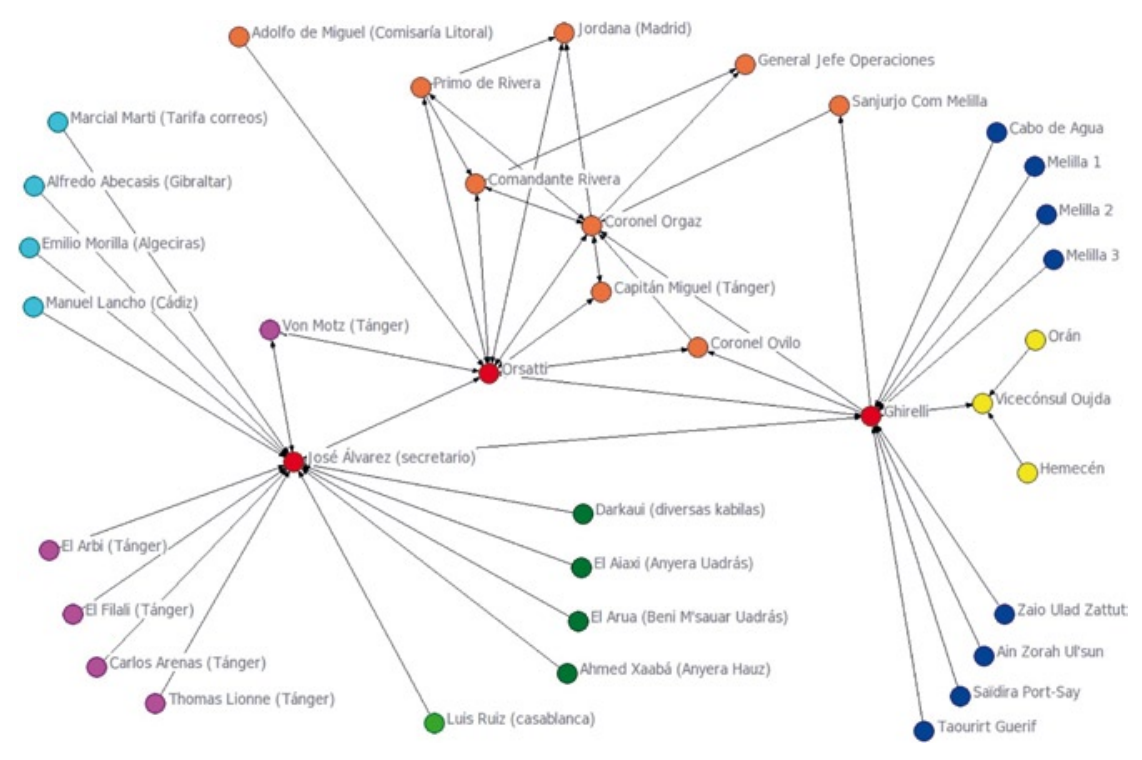

Figura 1

A pesar de la explicación del camino principal de la información (desde el espía en el campo hasta el general jefe de operaciones), como se puede observar en el gráfico hubo otros caminos u otros tipos de intercambios de información. Por ejemplo entre Ghirelli y la Comandancia de Melilla, con el coronel Ovilo en Málaga y con el coronel Orgaz. Estas comunicaciones no fueron muy frecuentes, pero existieron, sobre todo entre Ghirelli y Orgaz. Es destacar también la figura del capitán Joaquín Miguel, que como indiqué en páginas anteriores, se incorporó a la refundada Oficina de Información de Tánger en abril de 1925. Aunque él no pertenecía formalmente a los Servicios Especiales Reservados, sí tuvo una comunicación fluida con Orsatti y con el coronel Orgaz. Él trabajaba sobre todo en las kabilas cercanas a Tánger y sus informaciones también las recibía el general jefe de operaciones.

Debido a la naturaleza del servicio y a la absoluta confidencialidad de la información, excepto el grupo de los militares, la mayoría de los actores de la red ni siquiera tenían comunicación entre sí. Ni los espías distribuidos en el territorio se comunicaron con el grupo de los militares, ni éstos 
lo hicieron nunca con los espías. La barrera formada por Orsatti, Ghirelli y José Álvarez era y debía ser infranqueable.

\section{El trabajo propiamente dicho}

Como he apuntado anteriormente, Ghirelli siempre fue un agente incómodo y en el fondo nadie confiaba en él, pero era la persona que mejor conocía la mentalidad de los marroquíes de la zona oriental. Antes del desastre de Annual fue colaborador del general Fernández Silvestre. Este fue el motivo por el que fue contratado para este servicio. Pero siempre se quejó de que debía ser mejor pagado. A mediados de 1925, cuando el general Goded sustituyó a Sanjurjo en la Comandancia de Melilla, fue despedido del servicio. No obstante, no lo fue por sus exigencias económicas, sino por realizar mal su trabajo. Formalmente sus informes estaban muy bien ordenados y clasificados, pero excepto algunos sobre la cultura marroquí, la política colonial francesa y la religión, que fueron muy buenos, el resto eran datos y descripciones de acontecimientos sin filtrar y sin analizar, prácticamente tomados en bruto de sus agentes, con infinidad de nombres, lo cual contenía algunos errores. Obviamente no toda la información era inservible, porque debido a la cantidad de datos que aportaba necesariamente muchos de ellos sirvieron, primero para conocer las acciones del enemigo, especialmente movimientos de tropas y armamento y, después, para hacer algún tipo de acción en el futuro. Pero el problema que tenían los informes de Ghirelli era doble. Por un lado, esa enorme cantidad de datos dificultaba la tarea de análisis y, sobre todo, la de relacionar unos con otros. En segundo lugar, más grave, fue que mantuvo como verdaderas algunas informaciones que el equipo de Orsatti, a través de otras fuentes, descubrieron que eran falsas. Ghirelli no parecía poner mucho empeño en contrastar las informaciones de sus agentes para verificar si eran verdaderas o falsas. Por ejemplo: sostuvo en sus informes durante unos meses que Abd-elKrim había muerto. Orsatti le tuvo que corregir para que dejara de transmitir eso, porque sabían que seguía vivo. O, también, cuando mantuvo que en una reunión de la plana mayor del ejército rifeño, tras una discusión, Abd-el-Krim mató con su pistola delante de todos a Azerkan, apodado «pajarito». Azerkan fue el miembro más destacado de la delegación rifeña en las conversaciones de paz que tuvieron lugar en Uxda entre abril y mayo de 1926, por lo tanto no había muerto. Igualmente, 
las desavenencias con Orgaz aumentaron. En el fondo, todos estaban hartos de sus exigencias económicas y, a la vez, tener tan malos resultados; en lugar de facilitar el trabajo a los analistas lo que hacía era complicar aún más el trabajo al entregar la información sin filtrar y casi sin contrastar. Orsatti le confesó a Orgaz que llevaba seis meses sin hablarle, haciendo el ex coronel Álvarez Cabrera de intermediario con el italiano. Su expulsión no sorprendió a nadie. Es cierto que la zona oriental quedó desatendida respecto a las informaciones que se necesitaban, pero ya la guerra estaba muy avanzada y, sobre todo, el desembarco de Alhucemas ya estaba planificado y se iba a producir apenas un mes después de su despido. En consecuencia, el avance militar se haría con o sin información de los espías de Ghirelli. En este caso para descubrir las defensas de la bahía de Alhucemas, la aviación hizo un trabajo más eficaz.

Los informes de Orsatti eran más cortos, pero más concisos. Estaban mecanografiados en hojas azules y firmados por él; a veces también los enviaba escritos a mano. El título del tema principal del informe lo escribía en mayúscula y su contenido correspondía a lo que indicaba el título, de esta forma facilitaba la información para los analistas del servicio de la Inspección General de Intervenciones. Aparte de su buena redacción, la información solía estar contrastada; y en el caso de que no lo estuviera, avisaba de su fiabilidad. Distinguía siempre lo que era una buena información que merecía ser investigada para así ampliarla y verificarla, desgranándola de los simples rumores o chismes.

A continuación cito dos informes concretos, muy breves, a modo de ejemplo, el primero de Orsatti y el segundo de Ghirelli:

«EMBOSCADAS ENEMIGAS. Según informadores indígenas, el enemigo se propone sorprender en estos mismos días a los siguientes grupos nuestros: A) Nueve soldados encargados de la descubierta en Hayra Tuila (Piedra Larga), cerca de Seguedla. B) Siete soldados que todas las mañanas salen del Blockhaus del MEDIAR para hacer la descubierta. C) los soldados que hacen la aguada en el antiguo sendero de CUESTA COLORADA y salen del Blockhaus que se halla por encima de la aguada.

Tánger, 2 de enero de $1925^{25}$ »

25 Este breve informe se encuentra en caja A.G.A. 81/674, título de la carpetilla «Campaña. Política. Campaña 1924-27. SERVICIOS ESPECIALES DE INFORMACIÓN (reservado). Movimientos del enemigo. Zona Occidental. Zona Oriental». 
«S: D. Nota n. ${ }^{\circ}$ 1-4 de enero de 1925

\section{CONTRABANDO DE ARMAS Y MUNICIONES DE LA ZONA FRANCESA}

Con relación a lo señalado en nuestra nota reservada $n$. $^{\circ} 32 \mathrm{R}$ del 30 de diciembre de 1924, sobre el contrabando de armas y municiones por automóviles procedentes de la zona francesa, recibimos por otro conducto la información siguiente:

En la noche del día 28/12/24, salieron de Imedlem, puesto francés situado en la región meridional de Beni Bu Yahí en los límites con la kabila de Metalsa y al sur de la posición francesa de Haci Uenzga, dos camiones, cargados, el uno de fusiles Lebel modelo arbaía y tsaía y el otro de cajas de municiones, bombas de mano y picos y palas. Estos camiones fueron escoltados por 25 gumiers franceses hasta la casa del Chej Alí Hadech el Fetuchi el Metalsa, en donde llegaron al amanecer.

De allí los gumiers franceses volvieron a Imedlem.

El Kaid el Iazid el Uariagli que estaba en el Sebt en Ain Amar con su gente, salió a encontrar a dichos camiones en la casa del Chej Alí Hadech, llevando acémilas para cargar el contenido de los camiones y llevarlo a Sidi Alí bu Rekba, como efectivamente se hizo, volviendo después los camiones a su punto de partida ${ }^{26} \gg$.

Algunos informes tienen notas escritas a lápiz al margen de los títulos y con diferente caligrafía que la de Orsatti y Ghirelli, lo cual demuestra la existencia de diferentes grados de analistas dentro del ejército. El proceso de tratamiento de la información era muy rudimentario, pero no disponían de otros medios, por lo tanto había que trabajar con ellos. Los ítems más recurrentes de los documentos eran: personal, informaciones zona francesa, prisioneros y movimientos enemigos. Una vez clasificados, se seleccionaban los datos concretos para dilucidar y desgranar la información útil de la que no lo era, aplicándose el criterio de verdadero o falso por su contenido y por la urgencia que exigiera una determinada información. La información útil se clasificaba con el criterio temporal, es decir, si precisaba una actuación inmediata o si era para archivar o tener en cuenta para más adelante. Por ejemplo: si el es-

${ }^{26}$ Caja A.G.A. 81/675, título de la carpetilla «Campaña. Política. Campaña 1924-27. Servicios Especiales de Información (Reservado). Contrabando y sospechosos». 
pía detectaba movimiento de tropas enemigas en una zona, o el emplazamiento de un cañón en un lugar concreto, entonces inmediatamente se daba el aviso al departamento correspondiente del ejército de operaciones para que actuara en consecuencia, enviando tropas, preparando una emboscada u ordenando que algún avión bombardeara el lugar. Lógicamente, según fuera la importancia del caso así se actuaba. El tiempo que se tardaba en transmitir la orden era determinante para el éxito o el fracaso.

Pero la importancia de los Servicios Especiales Reservados no radica únicamente en el conocimiento instrumental, es decir, la información militar concreta sobre el armamento o los movimientos del enemigo, sino también en incluir como información relevante datos sociológicos, religiosos y políticos de la población. Desde mi punto de vista, esta fue la principal aportación de este organismo, sus informes solían contener este tipo de datos. Aunque Ghirelli fuera más desordenado que Orsatti en la redacción de los informes, en este aspecto hay que valorarle correctamente. Orsatti sabía que el italiano era un buen estudioso de la población marroquí y su cultura, por lo tanto incluyó algunos de los ensayos sociológicos y religiosos ya redactados anteriormente por él, para que los analistas los estudiaran.

El servicio tuvo unos resultados tangibles objetivables:

- En primer lugar, gracias a los agentes dirigidos por Orsatti, se conocieron los caminos y las rutas por donde se transportaban las mercancías desde Tánger hacia las cabilas rebeldes y se planificaron las emboscadas correspondientes. La consecuencia fue que en muy poco tiempo disminuyeron los suministros, aunque ello no implicó que se cortaran del todo.

- En segundo lugar, se conocieron mejor los movimientos de las tropas rifeñas, cómo estaban pertrechadas y qué planes pretendían hacer.

- En tercer lugar, se identificó mejor y a más personas de las que ya se conocían que eran sospechosas o estaban involucradas en manejos e intrigas clandestinas en Tánger, tanto europeos como marroquíes, describiendo nombres, movimientos, actividades, lugares frecuentados y relaciones que tenían. Las actividades a las que se dedicaban eran, o bien contrabando de diverso tipo, o bien intentos de colaboración con los rebeldes, o bien periodistas extranjeros. En este aspecto la colaboración con la Oficina 
de Información de Tánger dirigida por el capitán Miguel fue muy eficaz ${ }^{27}$.

- En cuarto lugar, se pudo identificar y contactar con las personas influyentes y notables de las kabilas para sondearlos e iniciar los trabajos de negociación de la paz, desarme y sometimiento de las kabilas al Majzen jalifiano. Esta labor la dirigió con éxito el coronel Orgaz desde principios de 1925 y durante 1926, pero fue Orsatti quien facilitó los contactos y las conversaciones.

- Y en quinto lugar, se amplió el conocimiento de la cultura marroquí, lo cual, a medio plazo, facilitó la difícil convivencia tras la guerra. Esto fue algo más lento, pero al menos se pusieron las bases.

Los Servicios Especiales Reservados se cancelaron en febrero de 1926. Como he indicado, toda esta labor fue continuada después por la Oficina Mixta Hipano-Francesa, con mayor sistematización y precisión en la recogida de la información, el registro de los nombres, las actividades y las relaciones de las personas sospechosas o vigiladas, las rutas del contrabando, los tipos de mercancías e incluso las publicaciones. El 28 de noviembre de 1925 Orsatti escribió una carta al primer director de la Oficina Mixta, el teniente coronel Salvador Múgica Buhigas, con quien ya había hablado unos días antes en Madrid, dándole la enhorabuena por el nombramiento y ofreciéndole todo tipo de ayuda y colaboración ${ }^{28}$. Ricardo Ruiz Orsatti regresó a su trabajo habitual como inspector de escuelas árabes y posteriormente fue nombrado jefe del servicio de higiene del ayuntamiento de Tánger. Publicó varios libros, de los cuales cabe destacar una monografía sobre la kabila de Anyera. Murió en 1946 sin hablar nunca públicamente de estas actividades de espionaje en las que estuvo ocupado durante los tres años más cruentos de la Guerra del Rif.

27 Un ejemplo de esto es el expediente titulado «Indeseables de Tánger. Relación personal y datos sobre manejos», dentro de ese expediente se encuentra una carpetilla titulada «Relación de individuos residentes en Tánger, indígenas y extranjeros sospechosos de contrabando», todo ello en la caja A.G.A. 81/10430. Junto con cartas, telegramas e informes, hay una lista de personas europeas que por alguna razón - según los criterios de los militares y policías - , eran vigiladas. Para un estudio de los europeos que estuvieron involucrados en la Guerra del Rif, desde contrabandistas, espías, colaboradores con los rebeldes, periodistas o simples vagabundos, véase Sasse, 2006.

${ }^{28}$ Esta carta se encuentra en la caja A.G.A. 81/10417, expediente titulado «Cartas confidenciales Ruiz Orsatti de Tánger». Se incluyen también algunos informes de espionaje y cartas, entre otros, a Primo de Rivera y al General Jordana. 


\section{Conclusiones}

Son varias las conclusiones que podemos sacar del estudio de este organismo y, por ende, del estudio de los servicios secretos de un ejército o de un Estado.

En primer lugar, lo más obvio: las guerras no solo ocurren en los campos de batalla, también ocurren en los despachos y sin disparos. Esto lleva a la necesidad de poseer buena información, no solo del enemigo, sino también del contexto, para poder diseñar y aplicar estrategias. En este artículo se ha podido comprobar que tras unos caóticos inicios en la creación y organización de los servicios de inteligencia especializados en el Protectorado español de Marruecos, se pasó a una eficacia aceptable. Se supo rectificar, aunque la ineficiencia anterior fue demasiado costosa.

En segundo lugar, aunque el protagonismo principal recae en Ricardo Ruiz Orsatti, un funcionario civil, no obstante el protagonista es el propio organismo, desde el espía que estaba en el campo hasta el general que recibía la información y daba la orden concreta. En este aspecto hay que destacar la importancia de cuatro actores de la red descrita.

Primero al coronel retirado, primer ayudante de Orsatti, José Álvarez. Fue un eficaz mediador entre los espías y los mandos del ejército, especialmente la Inspección General de Intervención y Fuerzas Jalifianas de Tetuán. Su labor de contención fue determinante para mantener el servicio en secreto. Después el agente Von Motz. Sus informes fueron muy certeros respecto a saber quién era quién en la sociedad tangerina. A continuación el comandante Rivera, que fue en realidad el verdadero analista del servicio. Los informes que le entregaban tanto en la zona occidental por parte de Orsatti, como en la zona oriental por parte de Ghirelli, eran largos y con mucha información, que no siempre era relevante a corto plazo. Por lo tanto, desde un punto de vista práctico, había que reducir la información y sintetizarla en órdenes precisas. Por ejemplo, un informe de media página podría contener varios datos, muy interesantes todos, pero había que diferenciar lo urgente de lo importante para que el ejército de operaciones fuera eficaz. Asimismo, había que clasificar la información y catalogarla para poder usarla posteriormente y relacionar unos datos con otros. Por ejemplo, el nombre de un sospechoso podía aparecer en un informe, pero no aportaba más información. Un tiempo después volvía a aparecer ese nombre en otra circunstancia, por lo tanto ya se poseían dos datos de la misma persona, y así sucesivamente se podía ir reconstruyendo una trayectoria y ya se tenía una base sobre la cual investigar. Esa 
labor de clasificación, catalogación y posterior recuperación de la información - lo que ahora denominamos una base de datos - , lógicamente, no la podían hacer ni los espías ni los directores del organismo. Y, finalmente, como no podía ser de otro modo, Angelo Ghirelli. Soslayando los errores que cometió y sus reivindicaciones pecuniarias, lo relevante de él es que puso todo su conocimiento como arabista al servicio del ejército. En sus informes se percibe ese conocimiento de la religión musulmana, de las costumbres de los rifeños y de la política colonial francesa.

El estudio de este organismo de espionaje nos demuestra que el trabajo del espía y de los servicios secretos no puede consistir únicamente en conocer al enemigo en su aspecto meramente instrumental o bélico, según sean los objetivos militares marcados, sino que se requiere también un conocimiento más amplio, como por ejemplo, la estructura de su sociedad, su política, su moral, sus costumbres, etcétera. El primer objetivo en una guerra es vencer al enemigo; obvio. Pero si tras la victoria no se aplican los conocimientos sociológicos, el vencedor estará abocado a que el conflicto pueda perdurar. Independientemente de la tendencia política de Orsatti y Ghirelli, que no eran de izquierdas precisamente (muy conservador en el caso del español), hay que destacar la importancia que ambos dieron al conocimiento sociológico o cultural para poder llevar a cabo alguna acción de intervención y, también, la necesidad de ser muy cuidadosos a la hora de aplicar algún tipo de castigo a la población o algo que implicara algún ataque a sus costumbres. Por ejemplo, ambos conocían el fuerte carácter religioso de los marroquíes, en consecuencia, en algunos de sus informes señalaban el lugar donde estaba ubicado algún pequeño templo para rezar o de culto, para, en el caso de ataque, no fuera deteriorado, y si lo era, poder reconstruirlo en breve tiempo. Esto se hizo durante la Guerra del Rif y fueron Orsatti y Ghirelli los que advertían de estos detalles. Y es aquí donde considero que está la importancia de este organismo de inteligencia creado por Primo de Rivera: en que la información recogida y posteriormente procesada no solo fue instrumental desde el punto de vista bélico, sino que era conveniente ampliarla con datos sociológicos de diverso tipo para usarla tanto en la guerra como en la paz.

He indicado que el organismo que continuó el trabajo de recopilación de la información de los Servicios Especiales Reservados fue la Oficina Mixta Hispano-Francesa. El trabajo de esta Oficina fue el correspondiente al de cualquier organismo de policía: usar el conocimiento social para mantener el orden público. En su caso se trataba de recabar toda la información relevante para perseguir a los delincuentes, rebeldes, contrabandistas y co- 
munistas (para las autoridades de la época ser comunista era sinónimo de delincuente y agitador social). No obstante, fue la Escuela de Interventores el organismo que continuó el trabajo de recopilación de datos y creación del conocimiento sociológico, con orientación a gestionar la política y la Administración, sin menoscabo de usar esa información también para el control social y político. Aunque ya existía antes de la guerra, la metodología que tenía para la recopilación y procesamiento de la información no estaba muy elaborada, eso se fue desarrollando años después, sobre todo durante la Segunda República. Esta institución supo ver la necesidad de poseer un buen conocimiento de la sociedad si se quería llevar a cabo la gestión de los recursos y el desarrollo económico y social del territorio. La experiencia de los Servicios Especiales Reservados coadyuvó a implantar esta idea.

Por último, hay que indicar que debido a la carencia de documentos (al menos hasta ahora) no se ha podido hacer un estudio de los espías de Abd-el-Krim, que eran muy numerosos según lo hacían constatar los informes de Orsatti, de Ghirelli, del capitán Miguel e incluso de algunos vecinos y religiosos españoles residentes en Tánger que informaban a las autoridades españolas. No se puede saber si estaban organizados en un organismo especializado o actuaban de manera informal. Pero teniendo en cuenta la estructura organizativa de la República del Rif que creó Abd-el$\mathrm{Krim}^{29}$ y la forma en que estaban organizadas las harkas rifeñas, me inclino a pensar (lo planteo como hipótesis de investigación futura) que sí tenía que haber algún organismo o grupo que gestionara la información que proporcionaban los espías, aunque sin una estructura burocrática al modo europeo. Lo que sí se puede afirmar con bastante probabilidad de acierto es que a la vista de los informes de los militares españoles, el número de los espías del ejército rifeño se acercaría al número de habitantes que apoyaban la rebelión; es decir, casi todos (hombres, mujeres, niños y ancianos) ejercieron en algún momento alguna tarea de espionaje o traspaso de información. Con lo cual nos podemos hacer una idea, primero, de la dificultad que supuso para el ejército formar un equipo de espías marroquíes que colaborara con los españoles sin riesgo a ser traicionados, y, segundo, la gran eficacia que tenía la red de espías rifeños, porque cualquier ciudadano podría aportar algún tipo de información relevante de la situación del ejército y sus movimientos.

${ }^{29}$ Para una consulta resumida de cómo estaba organizada la República del Rif y su ejército, véase el libro del General Goded (Goded, 1932, p. 83-111). 


\section{Fuentes}

Todas las fuentes documentales consultadas para la elaboración de este artículo se encuentran en el Archivo General de la Administración, Fondo de África. Han sido consultadas más cajas de las citadas en las notas a pie de página, pero solo se hará un listado de las citadas. Lo ideal sería indicar también el título del expediente concreto, pero eso no siempre es posible porque o bien no está registrado en el catálogo del archivo o bien, simplemente, no hay expediente propiamente dicho. Las cajas mencionadas han sido: $81 / 636,81 / 680,81 / 689,81 / 673,81 / 674,81 / 675$, $81 / 676,81 / 9979,81 / 9980,81 / 9981,81 / 9984,81 / 10417,81 / 10430$. $81 / 10431,81 / 10494,81 / 10495,81 / 10598,81 / 12710$ y la $68 / 324$.

\section{Bibliografía}

Alcalde, J. \& GRupo de Investigación TeOría-UCM: Los servicios Secretos en España, E_Books, UCM, Madrid, 2008.

Atienza PeÑARocha, Antonio: Africanistas y junteros: el ejército español en África y el oficial José Enrique Varela Iglesias, Universidad Cardenal Herrera-CEU, Departamento de Humanidades, tesis doctoral, Valencia, 2012.

AyACHE, G.: Les origines de la guerre du Rif, Société Marocaine des Éditeurs Réunins \& Publications de la Sorbonne, Paris \& Rabat, 1981.

BACHOUD, Andrée: Los españoles ante las campañas de Marruecos, editorial Espasa, Madrid, 1998.

Blond Álvarez del Manzano, Carlos: «El protectorado. Firma del Convenio Hispano-Francés y Guerra del Rif 1912-1927», en Revista de Historia Militar, número extraordinario II, 2012, pp. 101-134.

BorgatTi, EveretT and FREEMAN: UCINET VI for windows. Software for Social Network Analysis. User's Guide. Analytic Technologies Inc. 2002.

CABAllero Echevarría, Fernando: Intervencionismo español en Marruecos (1898-1928): Análisis de factores que confluyen en un desastre militar, «Annual». Universidad Complutense de Madrid. Tesis doctoral, 2013.

Campos Martínez, José M.: Abd-el-Krim y el Protectorado, editorial Algazara, Málaga, 2000.

CARrasco GonZÁlez, Antonio Manuel: «El ordenamiento jurídico hispano-marroquí», en ARAGÓN REYES, Manuel (director): El Protectorado Español de Marruecos. La historia Trascendida, ediciones Iberdrola, Bilbao, 2013, páginas 57-79. 
CASTILlo JimÉNez, Juan Ramón: Los servicios de información e inteligencia bajo el mando militar en el Protectorado Español de Marruecos (1909-1929), Instituto de Estudios Ceutíes, Ceuta, 2014.

FERNÁNDEZ RIERA, Vicente: Xauen 1924: la campaña que evitó un nuevo Annual. Almena Ediciones, Madrid, 2013.

Fontella Ballesta, Salvador: «Las campañas del Rif», en Revista de Historia Militar, número extraordinario II, 2012, pp. 135-160.

Gershovich, Moshe: French Military Rule in Morocco. Colonialism and its Consequences, Frank Cass Publishers, London, 2000.

GIRAULT, René: Diplomatie européene et impérialismes (1871-1914), Masson, París, 1979.

Goded Llopis, Manuel: Marruecos: las etapas de la pacificación, Madrid, 1932.

HART, David Montgomery: «Clanes, linajes, comunidades locales y luchas en una tribu rifeña (Ait Uriaguel, Marruecos)», en HART, David Montgomery y RAHA AHMED, Rachid (eds.): La sociedad bereber del Rif marroquí. Sobre la teoría de la segmentariedad en el Magreb, editorial Universidad de Granada y Diputación Provincial de Granada, 1999, pp. 53-123.

HeIBERG, Morten y Ros Agudo, Manuel: La trama oculta de la Guerra Civil. Los servicios secretos de Franco 1936-1945, editorial Crítica, Barcelona, 2006.

HERNÁNDEZ Mir, Francisco: Del desastre a la victoria (1921-1926). Del Rif a Yebala, Librería Fernando Fe, Madrid, 1926.

Madariaga, María Rosa: En el barranco del lobo. Las guerras de Marruecos. Madrid, Alianza Editorial, 2005.

MadARIAGa, Rosa: España y el Rif. Crónica de una historia casi olvidada. Ciudad Autónoma de Melilla. U.N.E.D. Centro Asociado de Melilla, 2008.

MADARIAGA, Rosa: Abd-El-Krim El Jatabi: la lucha por la independencia. Madrid, Alianza Editorial, 2009.

Martín Corrales, Eloy y González Alcantud, José Antonio (coords.): La Conferencia de Algeciras en 1906: un banquete colonial, Ediciones Bellaterra, Barcelona, 2007.

Molina, José Luis: El análisis de redes sociales. Una introducción, Ediciones Bellaterra, Barcelona, 2001.

Morales Lezcano, Víctor: El colonialismo hispano-francés en Marruecos (1898-1927), Siglo XXI, Madrid, 1976.

Navarro Bonilla, Diego: «Estudios sobre inteligencia: Fundamentos para la Seguridad», en Cuadernos de Estrategia, n. $^{\circ}$ 127. Instituto Español de Estudios Estratégicos, M. de Defensa, 2002.

Navarro Bonilla, Diego y Esteban Navarro, Miguel Ángel (Coord.): Gestión del Conocimiento y Servicios de Inteligencia, UC3M-B.O.E.-I.E.E.E. (M. ${ }^{\circ}$ Defensa), Madrid, 2004.

PenNel, C.R.: La guerra del Rif. Abdelkrim El-Jattabi y su estado rifeño, Ciudades Autónomas de Ceuta y Melilla, Centro Asociado de la U.N.E.D. edición de 2001. 
Rivet, Daniel: Lyautey et L'Institution du Protectorat Français au Maroc (3 volumes), L'Harmattan, París, 1988.

Rosales PARDo, Ignacio Antonio: «La inteligencia en los procesos de toma de decisiones en la seguridad y defensa», en Cuadernos de Estrategia, n. ${ }^{\circ} 130$. Instituto Español de Estudios Estratégicos, 2005.

SANTÉ ABAL, José María: «Cómo prevenir que los conflictos sociales deriven en conflictos armados», en Revista del Instituto Español de Estudios Estratégi$\cos$, n. $^{\circ} 5,2015$.

SASSE, Dirk: Franzosen, Briten und Deutsche mi Rifkrieg 1921-1926. Spekulanten und Sympathisanten. Deserteure und Hasardeure in Dienste Abdelkrims, Pariser Historische Studien, Oldenbourg Wissenschaftsverlag GmbH, München, 2006.

Sola CAStaño, Emilio y Varriale, Gennaro (coord.): Detrás de las apariencias. Información y espionaje ( siglos XVI-XVII), Universidad de Alcalá de Henares, 2015.

SueIro Seonne, Susana: España en el Mediterráneo. Primo de Rivera y la «cuestión marroquí, 1923-1930, U.N.E.D. Madrid, 1993.

Torremocha Silva, Antonio (coord.): La Conferencia Internacional de Algeciras de 1906 cien años después. Congreso Internacional, Fundación Municipal de Cultura José Luis Cano, Algeciras, 2008.

Vilanova VAlero, José Luis: Los interventores. La piedra angular del Protectorado Español en Marruecos, Edicions Bellaterra, Barcelona, 2006.

Wasserman, S. \& Faust, K.: Social Network Analysis. Methods and Aplications, CambridgeUniversity Press, Cambridge, 1997.

Woolman, David S.: Rebels in the Riff. Abd El Krim and the Riff Rebellion, Standford University Press, 1968.

\section{Financiación}

Instituto de Estudios Ceutíes.

\section{Datos del autor}

Julián Antonio Paniagua López (jpaniagua@ugr.es). Licenciado en filosofía, doctor en antropología social. Ha sido profesor asociado en la Universidad Autónoma de Madrid, profesor sustituto interino en la Universidad de Granada y actualmente es profesor tutor de la U.N.E.D. Ha trabajado en estudios de empresas (La Seda de Barcelona, Fosforera Marroquí), en análisis de redes sociales y en los últimos años investiga el Protectorado Español de Marruecos, especialmente el contrabando de armas, el contrabando económico, espionaje y guerra del Rif. 